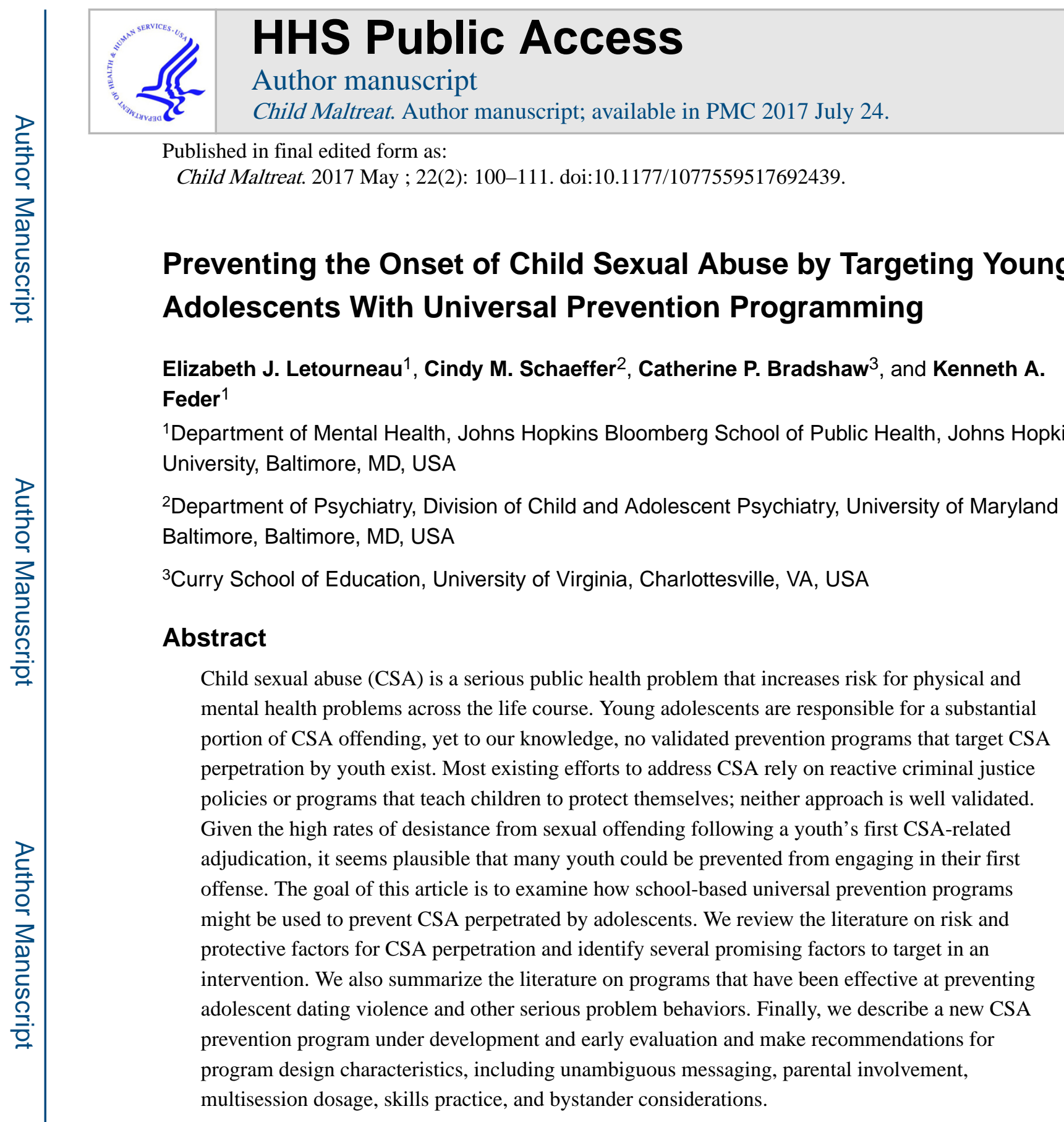

\title{
Keywords
}

adolescent; prevention; child sexual abuse

Reprints and permission: sagepub.com/journalsPermissions.nav

Corresponding Author: Elizabeth J. Letourneau, Department of Mental Health, Johns Hopkins Bloomberg School of Public Health, Johns Hopkins University, 415 N Washington St., Baltimore, MD 21231, USA. elizabethletourneau@jhu.edu.

The content is solely the responsibility of the authors and does not necessarily represent the official views of the National Institutes of Health or the Johns Hopkins Bloomberg School of Public Health.

Declaration of Conflicting Interests

The author(s) declared the following potential conflicts of interest with respect to the research, authorship, and/or publication of this article: K.A.F. was supported as a predoctoral by Department of Mental Health Scholar, Johns Hopkins Bloomberg School of Public Health. 
There is strong evidence that young adolescence represents the riskiest period for perpetrating sexual harm against younger children. Crime data and child sexual abuse (CSA) victim surveys indicate that a substantial portion of CSA is perpetrated not by adults but by youth (i.e., under the age of 18). In an analysis of national crime data, Finkelhor, Ormrod, and Chaffin (2009) found that youth were identified as perpetrators in about 35\% of all sex crime cases involving victims under age 18 and in about $50 \%$ of cases involving victims under age 12. Likewise, an earlier analysis of national crime data identified 14 years of age as the peak age for sexual offending against children among offenders of any age, and further reported that $40 \%$ of sexual offenses against children under age 12 were committed by other, usually slightly older children (Snyder, 2000). Surveys of CSA victims also indicate that a large proportion-more than 50\%—of completed or attempted CSA incidents were committed by youth (Finkelhor, Vanderminden, Turner, Shattuck, \& Hamby, 2014).

Many experts have previously noted the need for preventing the onset of sexual offending behaviors among youth and have recommended school-based approaches. For example, Wurtele and colleagues recommended that parents and educators clearly convey that it is harmful, immoral, and illegal for older children to engage younger children in sexual behavior and that parents encourage healthy sexual development of their children (Wurtele, 2009; Wurtele \& Kenny, 2011). Echoing recommendations originally proposed by Finkelhor and Daro (1997), Smallbone, Marshall, and Wortley (2008) have recommended, as part of a life-course developmental approach to the primary prevention of CSA, that health education curricula for young adolescents include a variety of foci such as the acceptance of sexual diversity, improved communication between partners, and modeling of sexual activities within a framework of mutual respect and affection between partners. They also suggest that curricula reinforce the important distinction between sexual thoughts and feelings about children on the one hand versus sexual behavior with children on the other.

In this article, we expand upon the work of these scholars to further argue for the development and evaluation of interventions aimed at preventing the onset of CSA perpetration by young adolescents. We review the extant literature regarding risk factors for adolescent-perpetrated CSA and the characteristics of youth who have sexually offended. We then examine evidence for school-based prevention programs that target adolescent perpetration of other forms of violence, including peer dating violence and bullying. We conclude with a description of a new school-based, youth-, and parent-focused universal prevention program currently being tested and provide general design recommendations for similar programs aimed at reducing the likelihood that older children will engage younger children in sexual behaviors.

\section{CSA as a Public Health Problem}

CSA remains a common and serious public health problem (Daro, 1994; Letourneau, Eaton, Bass, Berlin, \& Moore, 2014; McMahon \& Puett, 1999; Mercy, 1999; Whitaker et al., 2008). A meta-analysis of 271 studies from around the world indicated that approximately $18 \%$ of girls and $8 \%$ of boys self-reported having experienced CSA before age 18 (Stoltenborgh, van Ijzendoorn, Euser, \& Bakermans-Kranenburg, 2011). In the United States, an estimated 10$17 \%$ of girls and $4-6 \%$ of boys have experienced sexual abuse, assault, and/or harassment by 
late adolescence (Finkelhor, Shattuck, Turner, \& Hamby, 2014; Townsend \& Rheingold, 2013), and CSA is ranked as the 12th highest among 67 preventable risk factors contributing to the U.S. burden of disease (U.S. Burden of Disease Collaborators, 2013). The World Health Organization also recognizes CSA as a preventable risk factor that substantively contributes to the global burden of disease (Mathers, Stevens, \& Mascarenhas, 2009).

It is well known that CSA victimization confers substantial risk for severe mental, physical, and behavioral health problems across a victim's life course (Bedi et al., 2011; Dong et al., 2004; Noll, Horowitz, Bonanno, Trickett, \& Putnam, 2003; Noll, Zeller, Trickett, \& Putnam, 2007; Putnam, 2003; Sommarin, Kilbane, Mercy, Maloney-Kitts, \& Ligiero, 2014). CSA also increases risk for subsequent sexual and nonsexual victimization and criminal offending (Ogloff et al., 2012). CSA-related expenses (e.g., for treatment, for lost economic productivity) are estimated at US $\$ 210,000$ and US $\$ 310,000$ per male and female victim, respectively (Letourneau, Brown, Fang, Hassan, \& Mercy, 2017).

\section{Traditional Approaches to Preventing CSA Victimization}

Effective universal CSA prevention programs could have substantial public health benefits by reducing the risk of mental health problems, revictimization, and intergenerational transmission of abuse and also by reducing the monetary costs borne by victims, their families, and communities. However, most current efforts to address CSA are reactive criminal justice interventions focused on the identification, prosecution, punishment, and subsequent control of adjudicated offenders (Letourneau \& Levenson, 2010; Letourneau \& Shields, 2015). When prevention programs are implemented, most are designed to help potential victims protect themselves from abuse (Whitaker et al., 2008; Wurtele, 2009). There is growing recognition of the need for a more comprehensive approach to prevention, including approaches that specifically target potential perpetrators and the onset of CSA (Letourneau, Eaton, Bass, Berlin, \& Moore, 2014; Smallbone, Marshall, \& Wortley, 2008; Whitaker et al., 2008; Wurtele, 2009).

Since the 1970s, hundreds of resources to prevent CSA have been developed (for a review, see Baker, 2005). Many of these resources take the form of school-based child-focused prevention interventions that focus on educating children to protect themselves from victimization by recognizing, resisting, and reporting sexually abusive behaviors-the socalled 3 Rs of CSA prevention (Walsh, Zwi, Woolfenden, \& Shlonsky, 2015; Wurtele, 1987, $2002,2009)$. The use of such victim-focused prevention programs has declined over recent years, perhaps because schools have increased their focus on bullying prevention and other positive behavioral interventions (Finkelhor, Shattuck, et al., 2014). However, recent state and federal CSA prevention policy efforts continue to be dominated by this traditional focus, and many require public schools to implement child-focused CSA victimization prevention efforts (Bernier, 2015). Of the 27 states that have or are attempting to pass new CSA prevention-related legislation, only 2 make any reference to prevention of child-on-child perpetration (Bernier, 2015).

Unfortunately, the effectiveness of victim-focused prevention for helping children avoid CSA has never been clearly established. Finkelhor and colleagues have conducted two 
evaluations of victim-focused CSA prevention programs on the incidence of victimization. In the first, a longitudinal study, they surveyed a nationally representative sample of youths $(N=2,000)$ ages $10-16$ years at two time points 15 months apart (Finkelhor, Asdigian, \& Dziuba-Leatherman, 1995). Participants were asked about exposure to school-based crime prevention programming, victimization experiences, and other outcomes. Approximately $67 \%$ the sample reported having been exposed to violence prevention programs, many focused on CSA. However, exposure to such programming was not associated with decreased rates of CSA victimization. In a second, cross-sectional survey, Finkelhor, Vanderminden, Turner, Shattuck, and Hamby (2014) again evaluated the effects of exposure to violence prevention programming with a nationally representative sample of youths ( $N=$ 3,391 ) ages 5-17 years. Telephone interviews (conducted with parents of children under age 10 years and with youth aged 10 years or older) assessed lifetime and past-year exposure to school- or community-based crime prevention programming, past-year victimization experiences, and other outcomes. Approximately $65 \%$ of the sample reported having been exposed to violence prevention programming, although only about $21 \%$ to CSA-specific programming. Consistent with the longitudinal study, analyses failed to identify any effect for exposure to prevention programming on rates of CSA.

Finkelhor and colleagues, as well as others, have identified several benefits of victimfocused CSA prevention programming. For example, a recent Cochrane Review (Walsh et al., 2015) found that, relative to control conditions, school-based CSA prevention programs were associated with increased knowledge about sexual abuse and its prevention, particularly among older children (Grade 4 and above), and with increased disclosure of current or past abuse. In their longitudinal study, Finkelhor and colleagues also found that prevention programming increased disclosure of abuse (Finkelhor et al., 1995); however, this finding was not replicated in their cross-sectional study, possibly because fewer youth in that study were exposed to CSA-specific programming (Finkelhor, Shattuck, et al., 2014). We concur with others that more research is warranted to determine whether high-quality victim-focused CSA prevention programming delivered with fidelity can reduce risk of victimization or bring about other positive outcomes (Davis \& Gidycz, 2000; Topping \& Baron, 2009; Walsh et al., 2015). However, we also believe that after 40 years, it is time to broaden the focus and provide resources that encourage the development and rigorous evaluation of other approaches for the prevention of CSA. In particular, we believe there is compelling emerging research evidence suggesting the potential efficacy of efforts that seek to prevent the onset of CSA behavior by youth.

\section{Preventing the Onset of CSA Perpetration: An Adolescent-Focused}

\section{Approach}

In contrast to victim-focused prevention, we found few references in the published literature to programs focused on the prevention of CSA perpetration. One exception is the German Prevention Project Dunkelfeld (PPD), a program that aims to achieve both secondary prevention, by targeting men who are sexually interested in children and have never acted, as well as tertiary prevention, by targeting men who have acted on such attractions but who have not been caught doing so (Beier et al., 2009). Results from a pilot study $(N=75)$ 
suggest PPD is associated with improvements among men who have previously offended (e.g., reduced emotional deficits and offense-supportive cognitions, increased sexual selfregulation) but not among men who have never offended (Beier et al., 2015). These findings suggest that PPD might serve more as a tertiary rather than a primary or secondary prevention intervention. Indeed, characteristics of the PPD program, including in-person attendance at weekly 3-hr group sessions over the course of approximately 1 year, align more with treatment than with prevention efforts (Frieden, 2009). It bears noting that German policy prohibits the disclosure of information obtained during therapy sessions; by contrast, mandatory reporting laws in the United States and elsewhere require the disclosure of CSA-related information obtained during therapy, precluding provision of services to undetected offenders in the United States and many other countries. Regardless, there is a clear dearth of prevention programs that target nonoffenders. This may be due, in part, to public misconceptions about CSA perpetration. When people think of sexual offenders, they often envision sexually deviant and predatory adults with high likelihood of recidivism (Finkelhor, Ormrod, \& Chaffin, 2009; Letourneau, Eaton, et al., 2014; Mejia, Cheyne, \& Dorfman, 2012). The reality is quite different: Adolescents comprise a substantial portion of CSA perpetrators, and there is reason to believe their behavior is transient and modifiable.

\section{Characteristics of adolescent CSA perpetration}

Adolescent sexual offending appears to be highly transient, in that the vast majority of youth who sexually offend do not reoffend sexually. As youth age out of early adolescence, incident rates for perpetration against younger children decline sharply (Finkelhor et al., 2009). Caldwell (2010) reviewed 63 data sets examining sexual recidivism among more than 11,000 youth who had sexually offended. The mean 5-year sexual recidivism rate was $7 \%$. In an updated meta-analysis, Caldwell (2016) reviewed 106 data sets examining sexual recidivism rates among more than 33,000 youth who had sexually offended. Studies published during the last 15 years reveal a mean 5-year recidivism rate of $2.75 \%$. The decline in recidivism from $7 \%$ to $2.75 \%$ is supported by other sources demonstrating reductions in the rates of CSA since the 1990s (e.g., Finkelhor \& Jones, 2004). This high rate of desistance following an initial sex offense suggests that first offenses might also be preventable.

Moreover, relative to sexual offenses perpetrated by adults, adolescent offense patterns are characterized by lower severity, shorter duration, fewer incidents, closer relationships to victims, and are more often "crimes of opportunity" that occur in contexts of convenience, such as babysitting (Finkelhor \& Ormrod, 2001; Miranda \& Corcoran, 2000; Vandiver, 2006). Smallbone and colleagues (2008) noted that adolescents most often offended against younger children in the course of nurturing (vs. aggressive) activities, including babysitting and while playing. Relative to youth who sexually offend against peers or who commit nonsexual violent offenses, youth who sexually offend against younger children are, on average, less delinquent and have fewer behavioral and family problems (Seto \& Lalumière, 2010; van Wijk et al., 2006).

In summary, youth account for a large proportion of CSA. Their offenses appear to be more opportunistic than adult sex offenses, their likelihood of sexual recidivism is remarkably 
low, and they are relatively less delinquent than youth who commit other violent offenses. Taken together, as others have noted (e.g., Chaffin, 2008), these findings stand in opposition to the notion that most youth who sexually offend do so for deep-seated intractable reasons and support the promise of universal programs that seek to prevent the onset of CSA.

\section{Risk factors associated with the onset of adolescent CSA perpetration}

For universal prevention programs to be successful, they must target dynamic (i.e., malleable) risk factors related to the onset of CSA. However, research on risk factors associated with the onset of sexually abusive behavior is sparse and often limited to retrospective reports and cross-sectional designs that do not adequately address timing of factors relative to offending behaviors (Seto \& Lalumière, 2010; Smallbone et al., 2008; Tharp et al., 2013; Whitaker et al., 2008). To our knowledge, only one longitudinal study has been undertaken to prospectively identify such risk factors. The Vancouver longitudinal study includes three cohorts of children recruited at ages 3-5 years recruited from 2008 to 2009 who will be followed through adolescence (Lussier, Tzoumakis, Corrado, Reebye, \& Healey, 2011). Although none of these child participants have attained adolescence yet, initial publications from this ongoing study suggest that several neonatal factors (e.g., birth complications, teratogen exposure; Lussier et al., 2011) and early life experiences (e.g., interparental sexual coercion; Cale \& Lussier, 2016) influence sexual behavior in early childhood. However, the extent to which these factors will be associated with the onset of sexually abusive behavior remains unknown.

Data from another longitudinal study focused on general delinquency have been used to determine the extent to which youth who ultimately committed violent offenses differed from youth who did not and also, to attempt to differentiate youth who ultimately committed violent sexual offenses from youth who ultimately committed violent nonsexual offenses (van Wijk et al., 2005). In this study, violent and nonviolent groups differed significantly on 54 of the $66(81 \%)$ risk factors examined, including factors pertaining to delinquency, substance use, emotional/behavior problems, sexual behavior, attitudes, competence, family factors, and demographic factors. In contrast, only two factors were significantly different between violent sexual versus violent nonsexual offenders: Youth with violent sexual offenses were more likely to run away from home and had better academic achievement. These results suggest that the risk factors for both sexual and nonsexual aggression are similar and that sexual violence may be an extension of nonsexual violence (Smallbone et al., 2008). However, the relevance of this study to youth who sexually offend against younger children is unknown, since such youth were excluded from analyses.

Two meta-analyses suggest possible risk factors for the onset of adolescent offending against children. Whitaker and colleagues (2008) analyzed 89 studies comparing (mostly adult) sexual offenders against children (SOC) to three other groups: sexual offenders against adults (SOA), nonsexual offenders, and nonoffenders. Results indicated few differences between the SOC and SOA groups. In contrast, many differences emerged between SOCs and nonsexual offenders/nonoffenders, including "sexual problems" (i.e., sexualized coping, deviant sexual interest, sexual interest in children, sexual externalizing problems, and higher sex drive), sexual preoccupations, and other deviant cognitions (i.e., cognitions that 
supported sex crimes, adult-child sex, and minimized culpability). SOCs were also more likely than nonsexual offenders and nonoffenders to have a history of sexual or physical abuse, difficulty with intimate relationships, and social skills deficits.

Seto and Lalumière's (2010) meta-analysis focused specifically on adolescents and included studies that compared boys who had committed sexual offenses against children and/or peers with boys who had committed nonsexual offenses. Thirty-seven factors across 12 categories were examined. Overall, youth with sexual offenses did not differ statistically from youth with nonsexual offenses on the majority of factors (21/37 or 57\%). Relative to youth with nonsexual offenses, youth with sexual offenses had significantly less extensive criminal histories, fewer antisocial peers, and fewer substance use problems; these findings were even more pronounced for youth who had offended against younger children as compared to youth with peer/adult victims. Also, youth with sexual offenses were significantly more likely than nonsexual offenders to be rated as having atypical sexual interests and to have experienced CSA victimization as well as other forms of abuse and neglect, exposure to sex and pornography, and low self-esteem and social isolation. These two meta-analyses shed light on factors that might be associated with the onset of adolescent sexual offending against children.

\section{Contextual factors}

Examination of the specific contexts in which CSA occurs may also yield information on relevant factors to address with prevention programming. As previously noted, youthperpetrated sexual offenses often occur when older children or young teens mix with younger children in unsupervised settings such as when babysitting or playing. As such, adolescent sexual offenses often appear to be opportunistic offenses (Finkelhor \& Ormrod, 2001), the risk of which might be heightened when young adolescents experience a confusing mix of nurturing and sexual impulses toward younger children (Smallbone et al., 2008). We believe the risk of CSA might also be heightened by youths' lack of knowledge about and inexperience with sex-that is, these might not only be crimes of opportunity but also crimes of ignorance. For example, in a treatment outcome study of adolescents charged with sexual offenses (Letourneau et al., 2009, 2013), therapists in the experimental condition were trained to identify the specific factors associated with each youth's sexual offense ( $N=$ 64 youth). Thirty-one separate factors were identified, and low sex knowledge was among the top 10 of these, characterizing $25 \%$ of the sample. The remaining top 10 factors included having experienced abuse or neglect (87.5\% of the sample), low supervision/monitoring (82.8\%), negative peers (48.4\%), impulsivity (40.6\%), lack of boundaries (34.3\%), family problems (29.6\%), exposure to pornography (28.1\%), social problems (26.5\%), and problematic parental discipline practices (18.7\%; Kwiatkowski, Schaeffer, Ebnesajjad, Hall, \& Letourneau, in press).

\section{Protective factors associated with preventing the onset of adolescent CSA perpetration}

While there is scant information on factors associated with the onset of CSA behavior, there is even less information on factors protective against it (Worling \& Langton, 2015). Nevertheless, many authors have suggested that the development of empathy may be an important protective factor. For example, Tharp and colleagues (2013) conducted a 
qualitative review of studies on risk and protective factors for the onset of sexual violence by adolescents (of note, they specifically excluded studies on sexual abuse of younger children). The authors identified several potential protective factors, including feeling empathy for others, believing that others care, and having parents who used reasoning for conflict resolution. Worling and Langton (2015) evaluated risk and protective factors associated with adolescent sexual recidivism. In this prospective study, a measure of "affective strength" was predictive of desistance from sexual offending. The affective strength scale included assessment of a youth's ability to give and receive affection, express feelings, show concern for others, accept closeness, and acknowledge painful feelings. Tharp et al. identified the construct of affective strength is conceptually similar to empathy (Worling \& Langton, 2015). Likewise, in their integrated theory of CSA prevention, Smallbone et al. (2008) emphasize the role of empathy (or lack thereof) in as a developmental risk factor related to the onset of CSA.

\section{Summary of common risk and protective factors}

Given the substantial harm associated with CSA, we should know more than we do about the risk and protective factors associated with its onset. Most of the available research is severely limited by its reliance on cross-sectional, retrospective data, typically obtained from incarcerated or adjudicated groups. More systematic prospective studies that follow children and families over time, as with the Vancouver longitudinal study, are sorely needed. Nevertheless, some conclusions from the risk and protective literature are warranted.

First, the experience of early adversity and especially (but not only) CSA victimization appears to be related to the onset of CSA in adolescents. As a static variable, the experience of early adversity does not lend itself to universal, school-based prevention programs. Rather, the efforts will need to focus on prevention of early adversity and selected prevention efforts. As many have noted, evidence-based policy and practice designed to prevent early childhood adversity, particularly through efforts that promote positive parenting and improve affective bonding between parents and children, may reduce the likelihood of CSA perpetration (e.g., Smallbone et al., 2008; Whitaker et al., 2008). Despite decades of research on family-based prevention programs, we are unaware of any that have investigated whether program effects included reducing the likelihood of future CSA perpetration. We recommend adding sexual behavior outcomes, including measurement of adolescent sexual behavior with younger children, to studies that evaluate early prevention programs.

Second, review and meta-analytic findings reaffirm the need to ensure that treatment programs designed for victims of CSA and their families explicitly address the possibility of increased risk of future offending behavior. One obvious challenge is doing so in a way that does not further marginalize child victims. Trauma-focused cognitive behavioral therapy (CBT), a well-validated intervention that effectively addresses many of the mental and behavioral health problems associated with CSA, has also been associated with reduced sexualized and sexually inappropriate behaviors (Pollio, Deblinger, \& Runyon, 2011). More research documenting these effects and their mechanisms of action would be helpful additions to the literature. 
Third, the unsurprising finding that sexual problems might be associated with the onset of CSA suggests that specialized programs are needed to address atypical sexual interests when these occur among adolescents and to address sexualized coping and sexual preoccupation when these occur among children and adolescents. While these risk factors are modifiable, they also have low prevalence in child and adolescent populations, and thus are not appropriate targets for universal school-based prevention programs. Rather, well-validated CBT interventions for children with problem sexual behaviors (i.e., selected intervention) that directly involve caregivers have been found to reduce the likelihood of future problematic sexual behaviors and sexual offending (Carpentier, Silovsky, \& Chaffin, 2006; St. Amand, Bard, \& Silovsky, 2008). These programs are being extended for use with young adolescents with problematic sexual behavior or first-time illegal sexual behaviors (Silovsky, Hunter, \& Taylor, 2016). Ongoing research funded by the Office of Juvenile Justice and Delinquency Prevention should shed light on whether and how these extensions impact the onset and recurrence of CSA by adolescents.

Fourth, social skills deficits, including anxiety, loneliness, low self-esteem, and social isolation, may be associated with the onset of CSA perpetration. These dynamic risk factors can be addressed in universal school-based prevention programs that have a general socialemotional learning focus. Indeed, there are dozens of well-validated programs designed to promote social skills among children and adolescents (e.g., Durlak, Weissberg, \& Pachan, 2010). Designing CSA prevention modules for evaluation within the context of such programs might offer a relatively feasible way to identify and disseminate effective CSA prevention programming among youth characterized by such deficits.

Finally, the literature suggests that there are some dynamic risk and protective factors that lend themselves to universal prevention interventions. These include low empathy for young children, cognitions supportive of sex with young children, cognitions that minimize culpability for inappropriate or harmful sexual behaviors, and limited knowledge about what is and is not appropriate sexual behavior. Effective universal school-based prevention programming could provide a cost-effective way of preventing the onset of CSA and the many negative outcomes associated with these behaviors. In a recent report on child abuse and neglect research, the Institute of Medicine and National Research Council (2014) noted that "communities and public agencies continue to demand and support broadly targeted primary prevention strategies such as school-based violence-prevention education" in addition to programming for at-risk people and families (p. 264). In a subsequent section, we describe a CSA prevention intervention that is designed to address dynamic risk factors within the context of a school-based curriculum. First, however, we review school-based universal prevention interventions that have shown success in preventing peer-on-peer sexual harassment and violence.

\section{Prevention of Peer-on-Peer Sexual Harassment and Sexual Violence}

Since the 1990s, classroom-based universal prevention programs targeting problematic behavior by youth have been developed and evaluated, and many now have strong empirical support, including those focused on bullying (Bradshaw, 2015; Farrington \& Tofti, 2009), antisocial behavior (Hahn et al., 2007; Wilson \& Lipsey, 2007), drug abuse (Gottfredson \& 
Wilson, 2003), and risky sexual behaviors (Chin et al., 2012). In addition, the past two decades have seen an increase in the development and evaluation of school-based universal prevention programs that target the commission of peer-on-peer sexual harassment, sexual violence, and other problematic sexual behaviors. Several of these prevention programs have shown promise (Clinton-Sherrod et al., 2009; Foshee et al., 2004; Taylor, Stein, Mumford, \& Woods, 2013). We review programs that specifically target middle school-aged children, as these seem most relevant to informing youth-focused prevention interventions that target the onset of CSA (i.e., given a peak age of 14 years).

\section{Safe Dates}

Safe Dates (Foshee et al., 2004) is a school-based intervention to prevent dating violence. The program targets eighth- and ninth-grade students (typically ages 14-15 years). Safe Dates includes ten 45 -min sessions led by a health teacher. In addition, students put on a theater production about safe dating and compete in a poster presentation contest. The school-based intervention is supplemented by a set of community services including a crisis line, support groups, and parent materials for adolescents in an abusive relationship (Foshee et al., 1998).

The program targets theoretical predictors of dating violence and seeks to (1) change norms associated with partner violence, (2) decrease gender stereotyping, and (3) improve conflict management skills. In addition to primary prevention, the program seeks to promote secondary prevention by changing beliefs about the need for help and raising awareness about services for victims and perpetrators. In a cluster-randomized controlled trial with 14 schools and 1,700 participants, after 1 month, students who participated in the school-based Safe Dates program and had access to community services were less likely to report perpetrating psychological, physical, and sexual violence against their current partners than youth who received only the community services component of Safe Dates. Students who participated in the program were also less likely to believe dating violence is sometimes acceptable, less likely to hold sexist beliefs, and more likely to be aware of victim services. These norms and beliefs were the primary targets of the school-based program, and analyses supported their role as the primary mediators of the school-based intervention. One year after the intervention, while between-group differences in theoretical cognitive mediators persisted, between-group differences in perpetration did not (Foshee et al., 2004). However, after 4 years, participants who received the school-based Safe Dates intervention were both less likely to report perpetrating and less likely to report being a victim of sexual violence. This is notable, because the 1 month evaluation found an intervention effect only on perpetration, suggesting that the changing norms and conflict management skills that appear to prevent perpetration also help participants protect themselves from victimization, years after the trial (Foshee et al., 2004). Also of note, Safe Dates has been effectively adapted into alternative formats to lower costs. For example, the program was adapted into a curriculum called "Fourth R" which was integrated into health and physical education courses in Ontario. The curriculum of this adapted intervention taught sex negotiation, delay, and refusal skills and helped students define and rehearse responsibilities in a healthy relationship. Two-and-a-half years after the intervention, Fourth $\mathrm{R}$ recipients reported lower 
levels of dating violence perpetration than the control group, with much larger effects in boys than girls (Wolfe et al., 2009).

\section{Shifting boundaries}

Shifting boundaries was developed as an alternative to Safe Dates for younger students (typically 12-13 years) to prevent even earlier dating violence. The program also has somewhat different targets than Safe Dates. Informed by the theory of reasoned action, the shifting boundaries curriculum focuses on the legal consequences of dating violence, the constructed nature of gender roles, and healthy relationships. All lessons center on teaching students to determine and set personal boundaries. School personnel implement the sixsession curriculum over a period of 6-10 weeks. The shifting boundaries curriculum is supplemented by a building-based intervention. As part of the building-based intervention, students and teachers identify "hot spots" where sexual violence and harassment are often perpetrated, and increase adult supervision in these places. The building-based interventions also allow for students to receive temporary restraining orders (called respecting boundaries agreements) and include posting signs about sexual harassment (Taylor et al., 2013).

In a cluster-randomized trial with 20 schools and more than 2,500 students, schools were randomly assigned to receive the building and curricular intervention, the curricular intervention alone, the building intervention alone, or neither. Students who were exposed to both the classroom-based and building-based interventions reported lower incidence of sexual harassment and sexual violence perpetration and victimization. The building-based intervention alone was also effective at reducing sexual harassment perpetration and victimization and sexual violence perpetration (but not victimization); however, the classroom-based intervention alone was not effective at reducing violence or harassment (Taylor et al., 2013).

\section{Second step-Student success through prevention (SS-SSTP)}

SS-SSTP is a school-based violence prevention program consisting of 15 lessons for sixth graders and 13 for seventh graders. SS-SSTP targets multiple forms of violence, including peer aggression, peer victimization, homophobic name-calling, and sexual violence perpetration and victimization. The Grade 6 curriculum includes content related to empathy and communication, bullying, emotion regulation, problem-solving, and substance abuse prevention. The Grade 7 curriculum is similar, but the bullying content is expanded to include cyberbullying and sexual harassment. In a cluster randomized trial with 36 middle schools and more than 3,500 students in Illinois and Kansas, at the end of sixth grade, schools that received SS-SSTP had lower rates of physical aggression as compared to control schools that did not receive the intervention; SS-SSTP had almost no effect on any other forms of violence, including sexual violence victimization, and perpetration (Espelage, Sabina, Polanin, \& Brown, 2013). The lack of effects on sexual violence after sixth grade might be due to the fact that sexual behavior was not overtly addressed within the curriculum. However, at a 2-year follow-up after seventh grade (when sexual harassment was added to the curriculum), Illinois schools that received SS-SSTP had lower rates of sexual violence perpetration, although Kansas schools did not (Espelage, Sabina, Polanin, \& Brown, 2015). 
In summary, there is evidence that school-based programs can prevent sexual violence perpetration among adolescents when these programs overtly focus on sexual knowledge, beliefs, and behaviors versus having a more generic violence prevention focus. In addition to an overt focus on sexual knowledge, beliefs, and behaviors, it appears that a curricula-only program may be inadequate for young adolescents (Taylor et al., 2013). While Taylor and colleagues added building-based interventions to their curricula, many experts have highlighted the importance of including parent-focused components to youth prevention programs (Bradshaw, 2014, 2015; Farrington \& Tofti, 2009; Finkelhor, Vanderminden, et al., 2014; Finkelhor et al., 1995). Nevertheless, given the promising results of school-based universal prevention programs targeting peer-on-peer sexual harassment and sexual violence as well as other forms of interpersonal behaviors, it seems plausible to suggest that welldesigned school-based prevention programming could effectively prevent the onset of adolescent CSA. We next describe a new effort to do so.

\section{Prevention of Adolescent CSA Perpetration: Responsible Behavior With Younger Children (RBYC)}

With funding from the National Institute of Child Health and Human Development, we are developing and will test the feasibility of a school-based universal prevention program that targets sixth-grade youth and their parents. Our "RBYC" program is specifically designed to prevent the onset of CSA.

The pilot study will proceed in three phases: (1) a qualitative process, to ensure that RBYC content and procedures are relevant and acceptable to students, parents, and educators; (2) a rapid prototyping process to minimize the time to revision; and (3) a pilot randomized control trial to assess feasibility, acceptability, and early indicators of change on proximal factors (e.g., CSA-related skills, knowledge, and beliefs). Sexual behavior with younger children will be assessed, although the pilot randomized control trial is not powered to determine the significance of any effects on this ultimate outcome.

Albeit likely to change in response to Phases 1 and 2 activities, the intervention as presently conceived will consist of eight classroom sessions, each lasting approximately $30 \mathrm{~min}$, administered weekly over a 10-week (to allow for missed weeks or content spillover) period. For this initial feasibility study, RBYC intervention modules will be delivered by an implementation specialist hired, trained, and supervised by the project investigators. The sessions will be cofacilitated by a classroom teacher and presented during health classes. Session content will address factors hypothesized to increase risk of perpetration of CSA, including cognitive distortions, poor perspective-taking skills, and lack of clear expectations against CSA. To encourage empathy for younger children, initial sessions will engage students in classroom discussions of developmental differences between older and younger children, perspective-taking, and empathic responding to younger children. To improve sex knowledge, to encourage cognitions against sex with younger children, and to heighten a sense of culpability for such behavior, subsequent sessions will include an understanding of what CSA is, why it occurs, who is responsible, and how to avoid, prevent, and intervene in it. Perpetration, victimization, and bystander involvement will also be addressed. In addition, 
RBYC will incorporate best practices thought to increase the effects of youth-focused prevention programming, including high use of behavioral skills practice (e.g., role-plays), continuity between sessions, and parent-facilitated assignments (Bradshaw, 2014, 2015; Farrington \& Tofti, 2009). Regarding parental involvement, research highlights the significant role parents play in their children's sexual development (Aspy et al., 2007; Baptiste, Tolou-Shams, Miller, Mcbride, \& Paikoff, 2007; Crosby et al., 2006; DiClemente et al., 2001). More generally, an important element of effective youth-focused violence prevention programs is the substantive inclusion of parents (Bradshaw, 2014, 2015; Farrington \& Tofti, 2009). Accordingly, the RBYC intervention includes four parentfacilitated homework assignments interspersed throughout the program. These are based on the parenting components used in other school-based models (e.g., keep a clear mind; Jowers, Bradshaw, \& Gately, 2007; family checkup; Herman et al., 2014) and are designed to promote parental awareness of situational factors that increase risk for CSA (e.g., low parental monitoring), encourage parent-child communication about CSA, and establish clear family rules against sex with younger children.

The widely disseminated Olweus Bullying Prevention Program (OBPP; Olweus et al., 2007) serves as the model for structuring classroom sessions (i.e., opening activity, discussion questions, wrap-up) and for intervention manual organization (e.g., background, learner outcomes, materials needed, teacher tips, dig deeper ideas). Since many schools already implement OBPP or similar prevention programs, they can readily incorporate the RBYC modules into ongoing prevention activities. Alternatively, the modules will be specified sufficiently, so that schools can deliver them as a freestanding intervention. The development and initial evaluation of RBYC will continue through the end of 2018. If the feasibility and preliminary indicators are positive, we plan to conduct larger scale efficacy and effectiveness trials in the future.

\section{Prevention of Adolescent CSA Perpetration: Program Design Considerations}

We hope that this review will help spur the development and, especially, the evaluation of more CSA prevention programs. Toward that end, we provide some program design considerations addressing program timing and content, participant gender, parental involvement, and more general principals of prevention. For these, we draw from the sexual violence perpetration and victimization prevention literatures (Finkelhor et al., 1995; Finkelhor, Shattuck, et al., 2014; Smallbone et al., 2008; Tharp et al., 2013; Topping \& Baron, 2009; Walsh et al., 2015; Whitaker et al., 2008; Wurtele, 2009; Wurtele \& Kenny, 2011) as well as the broader literature on youth violence prevention (e.g., Bradshaw, 2014; Nation et al., 2003).

\section{Program timing}

Several authors have noted the importance not only of selecting modifiable factors that influence ultimate outcomes but also the timing of when such factors are targeted for change and their proximity to the desired behavior (Smallbone et al., 2008; Tharp et al., 2013). The onset of adolescent sexual abuse of younger children peaks at age 14; therefore, 
youthfocused CSA prevention programs must target children younger than 14 . The question is "how much younger?" If as we hypothesize relevant factors include low empathy for younger children, cognitions supporting sex with children, cognitions minimizing culpability for sex with children, and low sex knowledge, these seem most relevant to children on the cusp of sexuality, versus younger children for whom such concepts are less salient. Thus, for reasons of both salience and proximity to emerging sexual behavior, the developmental transition period between preadolescence and adolescence seems ideal for youth-focused CSA perpetration prevention programming (Smallbone et al., 2008). As such we recommend targeting children between the ages of 11 and 13 with such programming, recognizing that this narrow age span will miss some youth and recognizing the importance of prevention programming that targets different factors across childhood and indeed across the life course.

\section{Program content}

Including relevant content will be essential to the effectiveness of school-based prevention programming that focuses on adolescent sexual behavior against younger children. First and foremost, such programs must include content that unambiguously addresses sexual behavior between children. While this may seem obvious, there are examples of programs that seek to influence youth sexual behavior without overtly discussing it (e.g., see, Espelage et al., 2013). Programs that deliver more general violence prevention messages and training may be more suitable for younger children. However, Finkelhor and colleagues reported that exposure to violence prevention programs in general (a minority of which pertained to CSA victimization prevention) was not associated with reduced rates of CSA victimization or perpetration (Finkelhor et al., 2014). We concur with others (e.g., Wurtele, 2009) that older children and adolescents will benefit from clear messaging regarding the inappropriateness and illegality of engaging younger children in sexual behavior.

\section{Gender of participants}

Some research has found stronger effects of sexual violence prevention curricula for boys than for girls (Wolfe et al., 2009). Coupled with the fact that boys are more likely to sexually offend than girls, some might argue that only boys should be exposed to prevention programming that targets the onset of CSA perpetration. However, girls do perpetrate sexual offenses against younger children (Finkelhor \& Ormrod, 2001; Snyder \& Sickmund, 2006). Moreover, both boys and girls serve important bystander roles with their peers, siblings, and other children. Additionally, research on peer-on-peer sexual violence prevention indicates that positive effects are enhanced, particularly for boys, when interventions are delivered in mixed gender classroom settings (Clinton-Sherrod et al., 2009). Whether these findings will hold for programming that targets adolescent sexual behavior directed against younger children is unknown, but it seems wise to start with supported program delivery characteristics. Thus, we recommend delivering CSA prevention programs within the context of mixed gender classroom settings.

\section{Parental involvement}

We believe that parental involvement is particularly relevant for CSA prevention programming. Parents play a central role in their children's sexual development. For 
example, parental monitoring and communication about sex have been associated with fewer adolescent sexual risk behaviors and lower rates of sexually transmitted infection (Aspy et al., 2007; Baptiste et al., 2007; Crosby et al., 2006; DiClemente et al., 2001). Parental involvement has also been a central component of effective prevention interventions targeting bullying (Bradshaw, 2014), in therapies for children with sexual behavior problems (Carpentier et al., 2006; St. Amand et al., 2008), and in therapies for adolescents who have engaged in abusive sexual behavior with younger children and peers (Letourneau et al., 2009, 2013; Silovsky et al., 2016). It follows that school-based CSA prevention programming should substantively involve parents (Walsh et al., 2015; Wurtele, 2009; Wurtele \& Kenny, 2011). Prevention goals might include promoting parental awareness of higher risk situations and other factors that may increase the risk of youth engaging younger children in sexual behaviors. Programming should also encourage parent-child communication about CSA and encourage the development of shared understandings between parents and youth regarding what constitutes appropriate and inappropriate sexual behavior.

We recognize that effectively engaging parents and other stakeholders including educators in CSA prevention programming is challenging for many reasons including sensitivities around adolescent sexual behavior in general and particularly sexual behavior with younger children (Chaffin, 2008; Chaffin \& Bonner, 1998). In our RBYC program, we address this challenge in several ways. First, we chose to frame the intervention around "responsible behavior" rather than "sexual behavior" with younger children. Given the many circumstances in which middle school children interact with younger children at home and in schools, we believe this responsible behavior frame will resonate with both parents and educators. Second, we plan to hold formative meetings with educators, parents, and middle school students in the first phase of this project, to ensure that content and approach are relevant and feasible from these groups' perspectives. Third, the activities we have designed for students to implement with their parents are brief and focused. Whereas it may be most effective to involve parents in every step of CSA prevention programming, even relatively brief interactions around relevant concepts might be helpful. As Bradshaw (2015) noted in her review of bullying prevention programs, even relatively unintrusive parent-youth activities (e.g., simply dining together) may be sufficient to prevent or buffer the effects of violence. Fourth, we have purposely designed the RBYC program to complement other widely disseminated prevention models. Appropriate framing of prevention issues, preparatory groundwork with relevant stakeholders, brief and targeted involvement of parents, and the design of interventions to align with existing programs and practices are just a few of the many ways in which investigators can improve parent engagement (Axford, Lehtonen, Kaoukji, Tobin, \& Berry, 2012) as well as stakeholder interest in and involvement with early prevention research efforts and the eventual dissemination of effective programs (Aarons, Hurlburt, \& Horwitz, 2011; Greenberg, 2004). We also suspect that the increased media coverage of adolescent sexual (mis)behavior in recent years may have increased the salience of CSA prevention for parents and educators who already routinely grapple with related concerns including teen sexting (Diliberto \& Mattey, 2009), online sexual harassment and abuse (Dombrowski, LeMasney, Ahia, \& Dickson, 2009), and graphic, sometimes violent sexual content in video games and other media (Browne \& Hamilton-Giachritsis, 
2005). Given this, we believe CSA programs that target the onset of CSA may be more acceptable to parents, educators, and other important stakeholders now than in prior years.

\section{General principles of effective prevention programs}

Until there is sufficient research available on CSA perpetration prevention programs to identify best practices, we encourage developers to adhere to principles of best practice that have been identified in related fields. In addition to the selection of relevant and malleable risk and protective factors, the appropriate developmental timing of programs, and the inclusion of parents, other best practices include (but are not limited to) sufficient multisession dosage, presentation of information in multiple formats, inclusion of opportunities to practice skills, ensuring program implementation with fidelity, and inclusion of outcome evaluations (Bradshaw, 2014, 2015; Farrington \& Tofti, 2009; Finkelhor, Vanderminden et al., 2014; Nation et al., 2003; Tharp et al., 2013; Topping \& Baron, 2009; Walsh et al., 2015; Whitaker et al., 2008). We believe these and similar considerations are relevant to the development of programs that focus on preventing the onset of CSA.

\section{Conclusions}

CSA is a serious public health problem of national and global concern. Universal schoolbased prevention approaches that aim to deter older children and adolescents from engaging younger children in sexual behaviors have the promise to prevent a sizable portion of CSA in a cost-effective manner. Existing school-based approaches most often focus on teaching potential victims to protect themselves from abuse, and while these programs are associated with some positive outcomes, it has not been established that they reduce the likelihood of victimization. More recently, promising programs have addressed peer-on-peer sexual harassment and violence, but these do not address sexual behavior against younger children. There is a need for school-based prevention programs that target the onset of CSA. The epidemiology of CSA indicates that young adolescent sexual abuse of younger children is relatively common and transient and frequently motivated by preventable factors. We should make the necessary investment to design, rigorously evaluate, and disseminate programs that effectively prevent older children from sexually abusing young children.

\section{Acknowledgments}

\section{Funding}

The author(s) disclosed receipt of the following financial support for the research, authorship, and/or publication of this article: Research reported in this publication was supported by the National Institute of Child Health and Human Development of the National Institutes of Health under award number R21HD083704.

\section{References}

Aarons GA, Hurlburt M, Horwitz SM. Advancing a conceptual model of evidence-based practice implementation in public service sectors. Administration and Policy in Mental Health and Mental Health Services Research. 2011; 38:4-23. [PubMed: 21197565]

Aspy C, Vesely SK, Oman RF, Rodine S, Marshall L, McLeroy K. Parental communication and youth sexual behavior. Journal of Adolescence. 2007; 30:449-466. [PubMed: 16750265]

Axford N, Lehtonen M, Kaoukji D, Tobin K, Berry V. Engaging parents in parenting programs: Lessons from research and practice. Children and Youth Services Research. 2012; 34:2061-2071. 
Baker, K. Preventing child sexual abuse: A national resource directory and handbook. Enola, PA: National Sexual Violence Resource Center; 2005.

Baptiste DR, Tolou-Shams M, Miller SR, Mcbride CK, Paikoff RL. Determinants of parental monitoring and preadolescent sexual risk situations among African American families living in urban public housing. Journal of Child and Family Studies. 2007; 16:261-274.

Bedi S, Nelson EC, Lynskey MT, McCutcheon VV, Heath AC, Madden PAF, Martin NG. Risk for suicidal thoughts and behavior after childhood sexual abuse in women and men. Suicide and LifeThreatening Behavior. 2011; 41:406-415. [PubMed: 21599726]

Beier KM, Ahlers CJ, Goecker D, Neutze J, Mundt IA, Hupp E, Schaefer GA. Can pedophiles be reached for primary prevention of child sexual abuse? First results of the Berlin Prevention Project Dunkelfeld (PPD). Journal of Forensic Psychiatry and Psychology. 2009; 20:851-867.

Beier KM, Grundmann D, Kuhle LF, Scherner G, Konrad A, Amelung T. The German Dunkelfeld project: A pilot study to prevent child sexual abuse and the use of child abusive images. Journal of Sexual Medicine. 2015; 12:529-542. [PubMed: 25471337]

Bernier, J. State and federal legislative efforts to prevent child sexual abuse: A Status Report. Chicago, IL: Prevent Child Abuse America; 2015. Retrieved from http://www.enoughabuse.org/images/ FINAL-Published_PCA_MK_CSAstatus_report_9-2015.pdf

Bradshaw CP. The role of families in preventing and buffering the effects of bullying. JAMA Pediatrics. 2014; 168:991-993. [PubMed: 25178737]

Bradshaw CP. Translating research to practice in bullying prevention. American Psychologist. 2015; 70:322-332. [PubMed: 25961313]

Browne KD, Hamilton-Giachritsis C. The influence of violent media on children and adolescence: A public health approach. Lancet. 2005; 365:702-710. [PubMed: 15721477]

Caldwell MF. Study characteristics and recidivism base rates in juvenile sex offender recidivism. International Journal of Offender Therapy and Comparative Criminology. 2010; 54:197-212. [PubMed: 19168638]

Caldwell MF. Quantifying the decline in juvenile sexual recidivism rates. Psychology, Public Policy and Law. 2016; 22:414-426.

Cale J, Lussier P. Sexual behavior in preschool children in the context of intra-parental violence and sexual coercion. Criminal Behavior and Mental Health. 2016

Carpentier MY, Silovsky JF, Chaffin M. Randomized trial of treatment for children with sexual behavior problems: Ten-year follow-up. Journal of Consulting and Clinical Psychology. 2006; 74:482-488. [PubMed: 16822105]

Chaffin M. Our minds are made up, don't confuse us with the facts: Commentary on policies concerning children with sexual behavior problems and juvenile sex offenders. Child Maltreatment. 2008; 13:110-121. [PubMed: 18408208]

Chaffin M, Bonner B. “Don't shoot, we're your children:” Have we gone too far in our response to adolescent sexual abusers and children with sexual behavior problems? Child Maltreatment. 1998; 3:314-316.

Chin HB, Sipe TA, Elder R, Mercer SL, Chattopadhyay SK, Jacob V, Santelli J. The effectiveness of group-based comprehensive risk-reduction and abstinence education interventions to prevent or reduce the risk of adolescent pregnancy, human immunodeficiency virus, and sexually transmitted infections: Two systematic reviews for the guide to community preventive services. American Journal of Preventive Medicine. 2012; 42:272-294. [PubMed: 22341164]

Clinton-Sherrod AM, Morgan-Lopez AA, Gibbs D, Hawkins SR, Hart L, Ball B, Littler N. Factors contributing to the effectiveness of four school-based sexual violence interventions. Health Promotion Practice. 2009; 10:19S-28S. [PubMed: 19136442]

Crosby R, Voisin D, Salazar LF, DiClemente RJ, Yarber WL, Caliendo AM. Family influences and biologically confirmed sexually transmitted infections among detained adolescents. American Journal of Orthopsychiatry. 2006; 76:389-394. [PubMed: 16981818]

Daro DA. Prevention of child sexual abuse. The Future of Children. 1994; 4:198-223. [PubMed: 7804764]

Davis MK, Gidycz CA. Child sexual abuse prevention programs: A meta-analysis. Journal of Clinical Child Psychology. 2000; 29:257-265. [PubMed: 10802834] 
DiClemente RJ, Wingood GM, Crosby R, Sionean C, Cobb BK, Harrington K, Oh MK. Parental monitoring: Association with adolescents' risk behaviors. Pediatrics. 2001; 107:1363-1368. [PubMed: 11389258]

Diliberto GM, Mattey E. Sexting: Just how much of a danger is it and what can school nurses do about it? NASN School Nurse. 2009; 24:262-267. [PubMed: 20440942]

Dombrowski SC, LeMasney JW, Ahia CE, Dickson SA. Protecting children from online sexual predators: Technological, psychoeducational, and legal considerations. Professional Psychology: Research and Practice. 2009; 35:65-73.

Dong M, Giles WH, Felittie VJ, Dube SR, Williams JE, Chapman DP, Anda RF. Insights into causal pathways for ischemic heart disease: Adverse childhood experiences study. Circulation. 2004; 110:1761-1766. [PubMed: 15381652]

Durlak JA, Weissberg RP, Pachan M. A meta-analysis of after-school programs that seek to promote personal and social skills in children and adolescents. Community Psychology. 2010; 45:294-309.

Espelage DL, Low S, Polanin JR, Brown EC. The impact of a middle school program to reduce aggression, victimization, and sexual violence. Journal of Adolescent Health. 2013; 53:180-186. [PubMed: 23643338]

Espelage DL, Low S, Polanin JR, Brown EC. Clinical trial of second step® middle-school program: Impact on aggression \& victimization. Journal of Applied Developmental Psychology. 2015; 37:52-63.

Farrington, DP., Tofti, MM. School-based programs to reduce bullying and victimization (Campbell systematic reviews. No. 6). Oslo, Norway: Campbell Corporation; 2009.

Finkelhor D, Asdigian N, Dziuba-Leatherman J. Victimization prevention programs for children: A follow-up. American Journal of Public Health. 1995; 85:1684-1689. [PubMed: 7503345]

Finkelhor, D., Daro, D. Prevention of child sexual abuse. In: Helfer, M.Kempe, R., Krugman, R., editors. The battered child. 5th. Chicago, IL: The University of Chicago Press; 1997. p. 615-626.

Finkelhor, D., Jones, LM. Explanations for the decline in child sexual abuse cases (Juvenile Justice Bulletin-NCJ199298, 1-12. Washington, DC: U.S. Government Printing Office; 2004.

Finkelhor, D., Ormrod, R. Crimes against children by babysitters (OJJDP Juvenile Justice Bulletin NCJ 189102). Washington, DC: U.S. Department of Justice, Office of Justice Programs, Office of Juvenile Justice and Delinquency Prevention; 2001 Sep.

Finkelhor, D., Ormrod, R., Chaffin, M. Juveniles who commit sex offenses against minors. Washington, DC: Office of Juvenile Justice and Delinquency Prevention; 2009.

Finkelhor D, Shattuck A, Turner HA, Hamby SL. The lifetime prevalence of child sexual abuse and sexual assault assessed in late adolescence. Journal of Adolescent Health. 2014; 55:329-333. [PubMed: 24582321]

Finkelhor D, Vanderminden J, Turner H, Shattuck A, Hamby S. Youth exposure to violence prevention programs in a national sample. Child Abuse \& Neglect. 2014; 38:677-686. [PubMed: 24630440]

Foshee VA, Bauman KE, Arriaga XB, Helms RW, Koch GG, Linder GF. An evaluation of Safe Dates, an adolescent dating violence prevention program. American Journal of Public Health. 1998; 88:45-50. [PubMed: 9584032]

Foshee VA, Bauman KE, Ennett ST, Linder GF, Benefield T, Suchindran C. Assessing the long-term effects of the Safe Dates program and a booster in preventing and reducing adolescent dating violence victimization and perpetration. American Journal of Public Health. 2004; 94:619-624. [PubMed: 15054015]

Frieden TR. A framework for public health action: The health impact pyramid. American Journal of Public Health. 2009; 100:590-595.

Gottfredson DC, Wilson DB. Characteristics of effective school-based substance abuse prevention. Prevention Science. 2003; 4:27-38. [PubMed: 12611417]

Greenberg MT. Current and future challenges in school-based prevention: The researcher perspective. Prevention Science. 2004; 5:5-13. [PubMed: 15058907]

Hahn R, Fuqua-Whitley D, Wethington H, Lowy J, Crosby A, Dahblerg L. Task Force on Community Prevention Services. Effectiveness of universal school-based programs to prevent violent and aggressive behavior: A systematic review. American Journal of Preventive Medicine. 2007; 33:S114-S129. [PubMed: 17675013] 
Herman, K., Reinke, W., Bradshaw, CP., Lochman, J., Borden, L., Darney, D. Increasing parental engagement in school-based interventions: Using team engagement and motivation methods. In: Weist, MD.Lever, NA.Bradshaw, CP., Owens, J., editors. Handbook of school mental health: Advancing practice and research. 2nd. New York, NY: Springer; 2014. p. 223-236.

Institute of Medicine \& National Research Council. New directions in child abuse and neglect research. Washington, DC: The National Academies Press; 2014.

Jowers KL, Bradshaw CP, Gately S. Taking school-based substance abuse prevention to scale: Districtwide implementation of keep a clear mind. Journal of Alcohol and Drug Education. 2007; 51:7391.

Kwiatkowski C, Schaeffer C, Ebnesajjad C, Hall B, Letourneau EJ. Drivers of youth problem sexual behavior and their relationship to MST treatment outcomes. (in press). Unpublished manuscript.

Letourneau EJ, Brown DS, Fang X, Hassan A, Mercy JA. The economic burden of child sexual abuse in the United States. 2017 Manuscript in preparation.

Letourneau EJ, Eaton WW, Bass J, Berlin FS, Moore SG. The need for a comprehensive public health approach to preventing child sexual abuse. Public Health Reports. 2014; 129:222-228. PMCID: PMC3982542. [PubMed: 24790251]

Letourneau EJ, Henggeler SW, Borduin CM, Schewe PA, McCart MR, Chapman JE, Saldana L. Multisystemic therapy for juvenile sexual offenders: 1-Year results from a randomized effectiveness trial. Journal of Family Psychology. 2009; 23:89-102. [PubMed: 19203163]

Letourneau EJ, Henggeler SW, McCart MR, Borduin CM, Schewe PA, Armstrong KS. Two-year follow-up of a randomized effectiveness trial evaluating MST for juveniles who sexually offend. Journal of Family Psychology. 2013; 27:978-985. [PubMed: 24188082]

Letourneau, EJ., Levenson, JS. Preventing sexual abuse: Community protection policies and practice. In: Meyers, J., editor. The APSAC handbook on child maltreatment. 3rd. Thousand Oaks, CA: Sage; 2010. p. 307-322.

Letourneau, EJ., Shields, RT. Ending child sexual abuse: A look at prevention efforts in the United States. In: Israelashviili, M., Romano, JL., editors. Cambridge handbook of international prevention science. Cambridge, MA: Cambridge University Press; 2015. p. 728-752.

Lussier P, Tzoumakis S, Healey J, Corrado R, Reebye P. Pre/perinatal adversities and behavioural outcomes in early childhood: Preliminary findings from the Vancouver longitudinal study. International Journal of Child, Youth, and Family Studies. 2011; 2:36-64.

Mathers, C., Stevens, G., Mascarenhas, M. Global health risks: Mortality and burden of disease attributable to selected major risk. Geneva, Switzerland: WHO; 2009.

McMahon PM, Puett RC. Child sexual abuse as a public health issue: Recommendations of an expert panel. Sex Abuse. 1999; 11:257-266. [PubMed: 10597642]

Mejia P, Cheyne A, Dorfman L. News coverage of child sexual abuse and prevention, 2007-2009. Journal of Child Sex Abuse. 2012; 21:470-487.

Mercy JA. Having new eyes: Viewing child sexual abuse as a public health problem. Sexual Abuse: A Journal of Research and Treatment. 1999; 11:317-321. [PubMed: 10597647]

Miranda AO, Corcoran CL. Comparison of perpetration characteristics between male juvenile and adult sexual offenders: preliminary results. Sex Abuse. 2000; 12:179-188. [PubMed: 10904990]

Nation M, Crusto C, Wandersman A, Kumpfer KL, Seybolt D, Morrissey-Kane E, Davino K. What works in prevention: Principles of effective prevention programs. American Psychologist. 2003; 58:449-456. [PubMed: 12971191]

Noll JG, Horowitz LA, Bonanno GA, Trickett PK, Putnam FW. Revictimization and self-harm in females who experienced childhood sexual abuse: Results from a prospective study. Journal of Interpersonal Violence. 2003; 18:1452-1471. [PubMed: 14678616]

Noll JG, Zeller MH, Trickett PK, Putnam FW. Obesity risk for female victims of childhood sexual abuse: A prospective study. Pediatrics. 2007; 120:e61-e67. [PubMed: 17606550]

Ogloff JRP, Cutajar MC, Mann E, Mullen P, Wei FTY, Hassan HAB, Yih TH. Child sexual abuse and subsequent offending and victimization: A 45 year follow-up study. Trends and Issues in Crime and Criminal Justice. 2012; 440:1-6.

Olweus, D., Limber, SP., Flerx, VC., Mullin, N., Riese, J., Snyder, M. Olweus Bullying Prevention Program teacher guide with DVD/CDROM. Center City, MN: Hazelden; 2007. 
Pollio, E., Deblinger, E., Runyon, M. Mental health treatment for the effects of child sexual abuse. In: Myers, JEB., editor. The APSAC handbook on child maltreatment. 3rd. Thousand Oaks, CA: Sage; 2011. p. 267-288.

Putnam FW. Ten-year research update review: Child sexual abuse. Journal of the American Academy of Child and Adolescent Psychiatry. 2003; 42:269-278. [PubMed: 12595779]

Seto MC, Lalumière ML. What is so special about male adolescent sexual offending? A review and test of explanations through meta-analysis. Psychological Bulletin. 2010; 136:526-575. [PubMed: 20565168]

Silovsky JF, Hunter M, Taylor E. Community-based services for youth with sexual behavior problems, child victims, and their families. 2016 Unpublished manuscript.

Smallbone, S., Marshall, WL., Wortley, R. Preventing child sexual abuse: Evidence, policy and practice. Portland, OR: Willan; 2008.

Snyder, HN., Sickmund, M. Juvenile offenders and victims: 2006 national report. Washington, DC: U.S. Department of Justice, Office of Justice Programs, Office of Juvenile Justice and Delinquency Prevention; 2006.

Snyder, HN. Sexual assault of young children as reported to law enforcement: Victim, incident and offender characteristics. A NIBRS statistical report. Washington, DC: Bureau of Justice Statistics, Office of Justice Programs, U.S. Department of Justice; 2000. from http://www.bjs.gov/ content/pub/pdf/saycrle.pdf [Retrieved July 19, 2016]

Sommarin C, Kilbane T, Mercy JA, Maloney-Kitts M, Ligiero DP. Preventing sexual violence and HIV in children. Journal of Acquired Immune Deficiency Syndrome. 2014; 66:S217-S223.

Stoltenborgh M, van Ijzendoorn MH, Euser EM, Bakermans-Kranenburg MJ. A global perspective on child sexual abuse: Meta-analysis of prevalence around the world. Child Maltreatment. 2011; 16:79-101. [PubMed: 21511741]

St. Amand A, Bard DE, Silovsky JF. Meta-analysis of treatment for child sexual behavior problems: Practice elements and outcomes. Child Maltreatment. 2008; 13:145-166. [PubMed: 18408211]

Taylor BG, Stein ND, Mumford EA, Woods D. Shifting boundaries: An experimental evaluation of a dating violence prevention program in middle schools. Prevention Science. 2013; 14:64-76. [PubMed: 23076726]

Tharp AT, DeGue S, Valle LA, Brookmeyer KA, Massetti GM, Matjasko JL. A systematic qualitative review of risk and protective factors for sexual violence perpetration. Trauma, Violence, and Abuse. 2013; 14:133-167.

Topping KJ, Baron IG. School-based child sexual abuse prevention programs: A review of effectiveness. Review of Educational Research. 2009; 79:431-463.

Townsend, C., Rheingold, AA. Estimating a child sexual abuse prevalence rate for practitioners: A review of child sexual abuse prevalence studies. Charleston, SC: Darkness to Light; 2013. Retrieved from www.D2L.org/1in10

U.S. Burden of Disease Collaborators. The state of US health, 1990-2010: Burden of diseases, injuries, and risk factors. Journal of the American Medical Association. 2013; 310:591-608. [PubMed: 23842577]

Vandiver DM. A prospective analysis of juvenile male sex offenders: Characteristics and recidivism rates as adults. Journal of Interpersonal Violence. 2006; 21:673-688. [PubMed: 16574639]

van Wijk A, Loeber R, Vermeiren R, Pardini D, Bullens R, Doreleijers T. Violent juvenile sex offenders compared with violent juvenile nonsex offenders: Explorative findings from the Pittsburgh youth study. Sexual Abuse: A Journal of Research and Treatment. 2005; 17:333-352. [PubMed: 16121842]

van Wijk A, Vermeiren R, Loeber R, 't Hart-Kerkhoffs L, Doreleijers T, Bullens R. Juvenile sex offenders compared to non-sex offenders: A review of the literature 1995-2005. Trauma, Violence, and Abuse. 2006; 7:227-243.

Walsh K, Zwi K, Woolfenden S, Shlonsky A. School-based education programmes for the prevention of child sexual abuse (Review). The Cochrane Library. 2015; 2015:1-121.

Whitaker DJ, Le B, Karl Hanson R, Baker CK, McMahon PM, Ryan G, Rice DD. Risk factors for the perpetration of child sexual abuse: A review and meta-analysis. Child Abuse and Neglect. 2008; 32:529-548. [PubMed: 18513795] 
Wilson SJ, Lipsey MJ. Effectiveness of school-based intervention programs on aggressive behavior: Update of a meta-analysis. American Journal of Preventive Medicine. 2007; 33:S130-S143. [PubMed: 17675014]

Wolfe DA, Crooks C, Jaffe P, Chiodo D, Hughes R, Ellis W, Donner A. A school-based program to prevent adolescent dating violence: A cluster randomized trial. JAMA Pediatrics. 2009; 163:692699.

Worling JR, Langton CM. A prospective investigation of factors that predict desistance from recidivism for adolescents who have sexually offended. Sexual Abuse: A Journal of Research and Treatment. 2015; 27:127-142. [PubMed: 25201880]

Wurtele SK. School-based sexual abuse prevention programs: A review. Child Abuse \& Neglect. 1987; 11:483-495. [PubMed: 3322515]

Wurtele, SK. School-based child sexual abuse prevention. In: Schewe, PA., editor. Preventing violence in relationships: Interventions. Washington, DC: American Psychological Association; 2002. p. 9-26.

Wurtele SK. Preventing sexual abuse of children in the 21st century: Preparing for challenges and opportunities. Journal of Child Sexual Abuse. 2009; 18:1-18. [PubMed: 19197612]

Wurtele SK, Kenny MC. Normative sexuality development in childhood: Implications for developmental guidance and prevention of childhood sexual abuse. Counseling and Human Development. 2011; 43:1-24. 